\title{
Solarização em microcosmo: efeito de materiais vegetais na sobrevivência de fitopatógenos de solo e na produção de voláteis
}

\author{
Marco Antonio Basseto ${ }^{1 *}$; César Júnior Bueno ${ }^{2}$; Fabio Augusto ${ }^{3}$; Márcio Pozzobon Pedroso ${ }^{4}$, Mayra Fontes Furlan \\ Carlos Roberto Padovani ${ }^{5}$, Edson Luiz Furtado ${ }^{1} \&$ Nilton Luiz de Souza ${ }^{1,6}$
}

${ }^{1}$ Faculdade de Ciências Agronômicas/UNESP, CP 237, 18610-307, Botucatu-SP; ${ }^{2}$ APTA/Instituto Biológico - Centro Experimental Central, CP 70, 13092-543, Campinas-SP ; ${ }^{3}$ Instituto de Química/UNICAMP, CP 6154, 13083-970, Campinas-SP; ${ }^{4}$ Departamento de Química/Universidade Federal de Lavras, 37200-000, Lavras-MG; ${ }^{5}$ Instituto de Biociências/UNESP, 18618-000, Botucatu-SP; ${ }^{6}$ In memorian

Autor para correspondência: Marco Antonio Basseto (mabplis@yahoo.com.br))

Data de chegada: 18/04/2011. Aceito para publicação em: 13/02/2012.

1748

RESUMO

Basseto, M. A.; Bueno, C. J.; Augusto, F.; Pedroso, M. P.; Furlan, M. F.; Padovani, C. R.; Furtado, E. L.; Souza, N. L. Solarização em microcosmo: efeito de materiais vegetais na sobrevivência de fitopatógenos de solo e na produção de voláteis. Summa Phytopathologica, v.38, n.2, p.123-130, 2012.

Além das brassicaceas associadas à solarização do solo, novos materiais vegetais como a mandioca e a mamona têm apresentado potencial no controle de fitopatógenos de solo. Assim, objetivou-se verificar os efeitos da incorporação e decomposição de parte aérea de brócolis, mamona e mandioca brava e mansa, associadas à solarização, em conjuntos de microcosmos, sob condições de ambiente controlado, na sobrevivência das estruturas de resistência de Fusarium oxysporum f. sp. lycopersici Raça 2, Macrophomina phaseolina, Rhizoctonia solani AG-4 HGI e Sclerotium rolfsii; e identificar e apontar o(s) volátil(eis) emanado(s) pela decomposição dos materiais, que poderia(m) estar correlacionado(s) com a inativação dos fitopatógenos. Quanto à sobrevivência dos patógenos, quatro ensaios idênticos foram instalados nos microcosmos, com quatro períodos de exposição independentes $(7,14,21$ e 28 dias). A identificação dos voláteis contou com ensaios realizados sob as mesmas condições da sobrevivência, mas em frascos âmbar e com cromatografia gasosa com detectores por espectrometria de massas (GC-MS) e por ionização em chama (GC-FID), utilizando a técnica de Microextração em Fase Sólida - SPME. Os tratamentos solo+materiais vegetais, ao longo dos períodos testados, reduziram a sobrevivência das estruturas de resistência de todos os fungos. No geral, destacaram-se o brócolis e a mandioca brava, além da mandioca mansa para S. rolfsii. Os voláteis identificados foram oriundos da decomposição de brócolis, mamona e mandioca mansa. Foram identificados 26, 37 e 29 compostos voláteis para brócolis, mamona e mandioca mansa, respectivamente. Correlações positivas e negativas foram observadas entre alguns voláteis e a média dos compostos com a sobrevivência das estruturas de resistência dos fitopatogênicos.

Palavras-chave adicionais: biofumigação, brócolis, mamona, mandioca, compostos voláteis

\section{ABSTRACT}

Basseto, M. A.; Bueno, C. J.; Augusto, F.; Pedroso, M. P.; Furlan, M. F.; Padovani, C. R.; Furtado, E. L. ; Souza, N. L. Solarization in microcosm: effect of plant materials on soil phytopathogen survival and volatile compound production. Summa Phytopathologica, v.38, n.2, p.123-130, 2012.

In addition to Brassicaceae species associated with soil solarization, new materials from plants such as cassava and castor bean have shown potential to control soil phytopathogens. Thus, the present study aimed to verify the effects of incorporation and decomposition of shoot of broccoli, castor bean, and bitter and sweet cassava, associated with solarization in microcosm sets under controlled environment conditions, on the survival of resistance structures from Fusarium oxysporum f. sp. lycopersici Race 2, Macrophomina phaseolina, Rhizoctonia solani AG-4 HGI and Sclerotium rolfsii; and to identify volatile compound(s) released by the decomposition of materials, which could be related to phytopathogen inactivation. As to pathogen survival, four identical assays were installed in the microcosms, with four independent exposure periods $(7,14,21$ and 28 days). To identify volatile compounds, assays were performed under the same survival conditions, but using amber glass bottles and gas chromatography with mass spectrometry (GC-MS) and flame ionization detectors (GC-FID), and adopting the Solid-Phase Microextraction Technique - SPME. The treatments soiltplant materials, over the tested periods, reduced the survival of resistance structures for all fungi. In general, expressive results were found for broccoli and bitter cassava, as well as sweet cassava against $S$. rolfsii. The identified volatile compounds were from broccoli, castor bean and sweet cassava decomposition. The number of volatile compounds identified for broccoli, castor bean and sweet cassava were 26, 37 and 29, respectively. Positive and negative correlations were detected among some volatile compounds and their mean values and the survival of resistance structures from phytopathogens. 
A associação de materiais vegetais específicos incorporados ao solo com a solarização (biofumigação) proporciona a inativação e a redução de inóculo de diversos fitopatógenos habitantes de solo, diminuindo a severidade de doenças $(18 ; 23)$. Há vários fatores apontados como responsáveis pela ação dessa associação: temperatura resultante da solarização (22); comunidade microbiana decompositora estimulada pela presença dos materiais vegetais incorporados ao solo $(6,7,18)$; atmosfera anaeróbica (26); e compostos voláteis resultantes da decomposição dos materiais vegetais (19). Dentre esses, os compostos voláteis são apontados como o diferencial quanto à eficácia no controle de fitopatógenos habitantes de solo, sobretudo os oriundos de brássicas $(3,11,12,21,22)$. Além das brássicas, outras fontes de matéria orgânica, tão ou mais eficientes no controle, são apontadas na literatura merecendo destaque a mamona (Ricinus comunis Crantz) e a mandioca (Manihot esculenta Crantz) (1).

Há poucos estudos sobre detecção de compostos voláteis emanados pela decomposição da mamona e da mandioca em associação com a solarização. Além disso, são escassos os estudos sobre a purificação e o contato de gases fungitóxicos emanados de plantas com fitopatógenos para comprovar a sua eficácia no controle. Há na literatura relatos de gases de isotiocianatos emanados, principalmente, a partir de brássicas e sua correlação no controle de fitopatógenos (11, 14, 18, 20).

A micro-extração em fase sólida (SPME, Solid Phase MicroExtraction) é uma técnica de extração e pré-concentração eficiente, introduzida no início da década de 90, extensivamente estudada e aplicada para a extração de compostos voláteis e semi-voláteis em diversas matrizes (2). A SPME permite uma extração rápida, simples, que dispensa o uso de solventes extratores e manipulação excessiva de amostra (25).

Os objetivos do presente trabalho foram: verificar os efeitos da incorporação e decomposição de parte aérea de brócolis, mamona e mandioca brava e mansa, associadas à solarização simulada em microcosmos, sob condições de ambiente controlado (BOD), na sobrevivência das estruturas de Fusarium oxysporum f. sp. lycopersici Raça 2, Macrophomina phaseolina, Rhizoctonia solani AG-4 HGI e Sclerotium rolfsii; e identificar e apontar o(s) volátil(eis) emanado(s) pela decomposição dos materiais que poderia(m) estar correlacionado(s) com a inativação dos fitopatógenos.

\section{MATERIAL E METODOS}

Os fitopatógenos estudados pertencem à Micoteca do Departamento de Produção Vegetal (DPV), da Faculdade de Ciências Agronômicas (FCA), UNESP, Campus de Botucatu - SP. Inicialmente, estes foram cultivados em meio Batata-Dextrose-Ágar (BDA) + oxitetraciclina $\left(0,05 \mathrm{mg} \mathrm{x} \mathrm{mL}^{-1}\right)$ e, posteriormente, transferidos para substratos específicos, auxiliando na produção das estruturas de resistência dos mesmos (4). Para F. oxysporum f. sp. lycopersici Raça 2 e $S$. rolfsii, a metodologia foi a adaptada por Bueno (4). Na produção das estruturas de resistência de M. phaseolina e R. solani AG-4 HGI foram utilizados frascos contendo substrato areno-orgânico estéril (17).

Os ensaios referentes à avaliação da sobrevivência das estruturas de resistência dos fitopatógenos foram instalados em estufas tipo $\mathrm{BOD}$, à temperatura de $37 \pm 2{ }^{\circ} \mathrm{C}$ (Figura $1 \mathrm{~A}$ ). As parcelas experimentais consistiram de microcosmos desenvolvidos por Bueno (4) (Figura 1B). Para a análise dos compostos voláteis, cada parcela experimental foi representada por dois frascos âmbar silanizados de $500 \mathrm{~mL}$ dotados

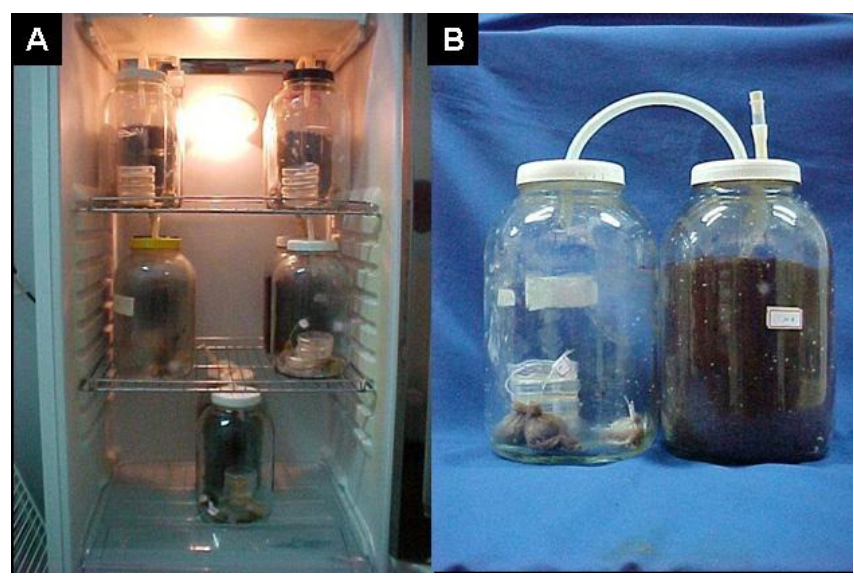

Figura 1. Esquema utilizado para simular o processo de solarização. Legenda: $1 \mathrm{~A}$ - Interior da estufa do tipo BOD com os conjuntos de microcosmos; 1B - Detalhe do conjunto de microcosmos.

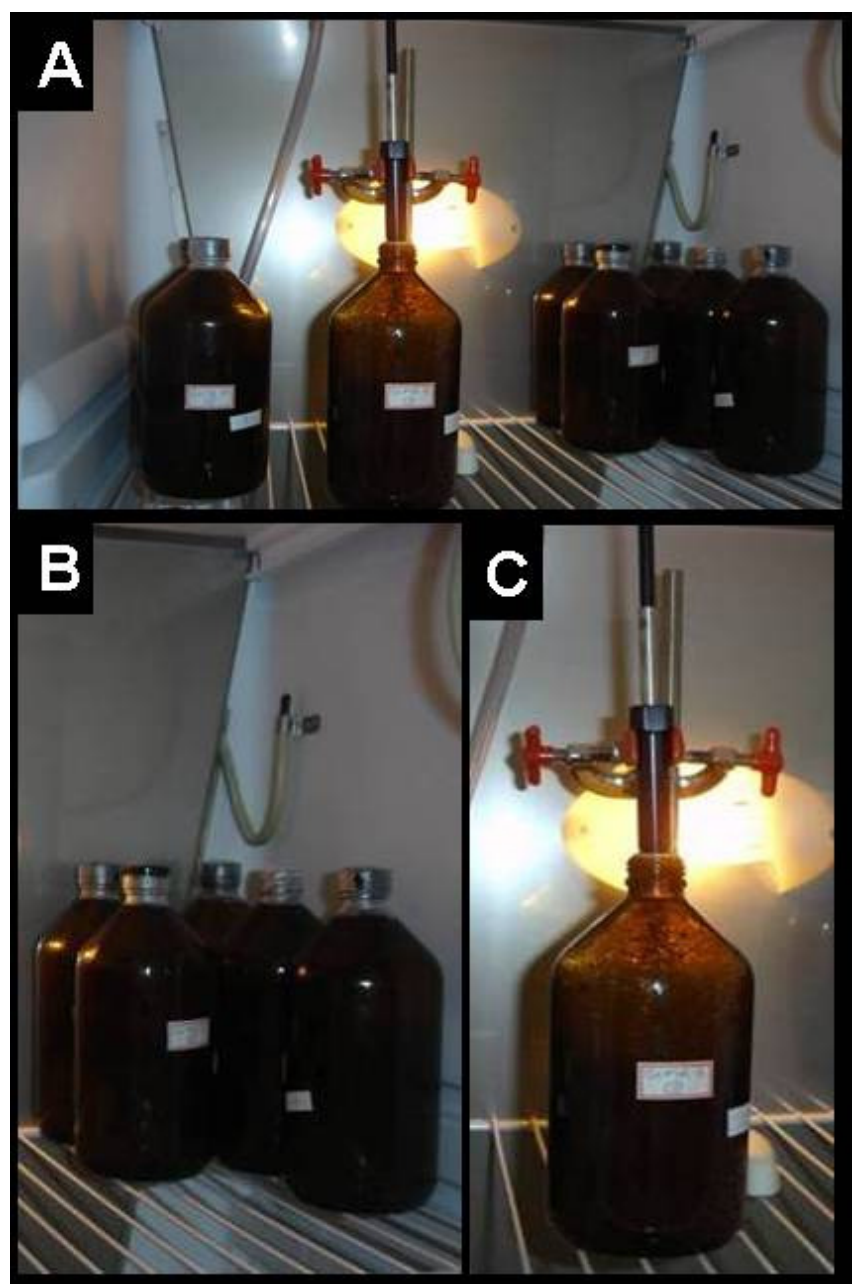

Figura 2. Extração de voláteis pela técnica SPME (Solid Phase MicroExtraction) em ambiente controlado. Legenda: 2A - Visão geral dos frascos âmbar e do processo de extração realizado no interior da BOD; 2B - Detalhe dos frascos âmbar devidamente vedados; 2C - Introdução e exposição da fibra aos voláteis acondicionados dentro do frasco. 
de uma tampa revestida por um septo de silicone (Figura 2).

Os materiais vegetais estudados foram ramos e folhas de mamona (Ricinus comunis L.), de mandioca brava e mansa (Manihot esculenta Crantz) e de brócolis (Brassica oleracea var. italica L.). Estes materiais foram incorporados ao solo e comparados com testemunha contendo solo.

O solo utilizado foi um Latossolo Vermelho Distroférrico de Textura Média (9) retirado de uma área agricultável da camada de dez centímetros de profundidade.

Nos microcosmos para análise de sobrevivência, os materiais vegetais foram triturados e incorporados no solo úmido (20\% de umidade) na proporção de três quilos de solo mais 75 gramas de material vegetal. Para os frascos âmbar, visando a avaliar os compostos voláteis, em $270 \mathrm{~g}$ de solo foram incorporados $8,1 \mathrm{~g}$ de cada material vegetal.

Para a análise da sobrevivência das estruturas de resistência dos fitopatógenos foram utilizadas bolsas de tecido sintético (náilon), contendo cada uma $10 \mathrm{~g}$ dos substratos infestados (talco e substrato areno-orgânico) com as estruturas dos fungos $F$. oxysporum f. sp. lycopersici Raça 2, M. phaseolina e $R$. solani. Para S. rolfsii, cada bolsa recebeu aproximadamente 100 escleródios (4).

Cada conjunto de microcosmo conteve uma bolsa (repetição) de cada organismo e as avaliações foram realizadas por plaqueamento das estruturas de resistência dos fitopatógenos em meios de cultura semiseletivos com cinco repetições (4). Para F. oxysporum f. sp. lycopersici Raça 2 foi utilizado o meio de Komada (16), para M. phaseolina o meio RB (5), para $R$. solani AG4 HGI o meio KHMP (15) e para $S$. rolfsii o BDA (4).

Para cada período e fungo analisado foi verificado o inóculo inicial no momento da montagem de cada ensaio (população inicial), além da sua sobrevivência em condições de ambiente de laboratório.

A técnica utilizada para a análise de voláteis foi a SPME (25). Os cromatógrafos utilizados na separação dos voláteis foram o GC-FID e o GC-MS. A fibra de SPME empregada foi a DVB/CAR/PDMS (Divinilbenzeno, Carboxen, Polidimetilsiloxano), assim como o próprio holder. Os demais reagentes empregados foram de grau de pureza P.A. A temperatura de extração por SPME foi de $37 \pm 2{ }^{\circ} \mathrm{C}$ simulando o processo de decomposição que ocorre no solo. O tempo de extração foi de 30 minutos e a fibra foi exposta no injetor do cromatógrafo por 10 minutos. A temperatura do injetor foi de $260{ }^{\circ} \mathrm{C}$ e do detector de $280^{\circ} \mathrm{C}$. O injetor foi operado no modo splitless em todas as injeções. Como gás de arraste foi usado He grau 5,0 a 0,8 $\mathrm{mL} \mathrm{min}^{-1}$. A rampa de temperatura escolhida foi a de $40^{\circ} \mathrm{C}$ por 10 minutos, $5^{\circ} \mathrm{C}$ por min. até $75^{\circ} \mathrm{C}, 15^{\circ} \mathrm{C}$ por min. até $165^{\circ} \mathrm{C}$ e $40^{\circ} \mathrm{C}$ por min. até $190^{\circ} \mathrm{C}$ por 3 minutos. A identificação dos voláteis (análise qualitativa) foi realizada pelo programa Automated Mass Spectral Deconvolution and Identification System (AMDIS) v. 2.63 equipada com a biblioteca NIST Mass Spectral Search Program v. 1.7 (NIST, Washington - DC, USA). Os espectros de massas obtidos foram comparados com os espectros da biblioteca. A análise semi-quantitativa foi obtida após a qualitativa observando as áreas dos picos de cada volátil nos cromatogramas. Com base nestas áreas, foi feita uma normalização dos valores para melhor vizualização dos resultados, utilizando como referência a maior área de um dado volátil (100\%) (PM) e correlacionando com os demais picos deste mesmo volátil em cada material vegetal.

O delineamento experimental adotado foi o inteiramente ao acaso, aleatorizando tanto os conjuntos de microcosmos dentro das BODs quanto os períodos de avaliação. $\mathrm{O}$ trabalho contou com quatro ensaios independentes, mas idênticos, diferindo apenas com relação aos períodos de avaliação: 7, 14, 21 e 28 dias.
Para os dados de sobrevivência dos fungos, a técnica de análise de variância utilizada foi o do esquema fatorial de sete tratamentos versus quatro fungos versus quatro períodos de avaliação, com quatro repetições por tratamento, considerando o vetor de resposta a sobrevivência dos quatro fungos. Os dados de sobrevivência foram transformados em porcentagem e, novamente, transformados em $\operatorname{arcsen} \sqrt{ }(\mathrm{X} / 100)$, o que possibilitou utilizar a análise paramétrica. Isto foi feito em razão da diferença de metodologia utilizada para avaliação da sobrevivência de F. oxysporum f. sp. lycopersici Raça 2 com relação aos demais fungos. $\mathrm{O}$ teste utilizado para comparação das médias de sobrevivência foi o de Scott-Knott ao nível de 5\% de probabilidade.

Realizou-se análise de correlação linear de Pearson entre as porcentagens relativas dos compostos voláteis emanados de cada material com os dados de sobrevivência das estruturas de resistência de cada fungo de solo.

\section{RESULTADOS E DISCUSSÃO}

A sobrevivência das estruturas de resistência dos fungos foi significativamente menor nos tratamentos contendo solo + material vegetal (Tabela 1)

Especificidade de toxicidade do material vegetal em relação a cada fitopatógeno foi observada (Tabela 1). Esta informação assemelha-se ao constatado por Ambrósio et al. (1).

Assim como foi observado por Ambrósio et al. (1), tanto em microcosmo como em campo, os tratamentos mais eficientes para todos os patógenos foram o solo + brócolis e solo + mandioca brava, além de solo + mandioca mansa para S. rolfsii. O tratamento solo + mamona apresentou controle dos patógenos, porém com eficiência inferior aos demais materiais (Tabela 1). O fato dos tratamentos solo e laboratório não terem diferido entre si é um importante indicativo de que a temperatura de $37^{\circ} \mathrm{C}$ não foi um fator limitante para a redução da sobrevivência das estruturas de resistência dos fitopatógenos. Além disso, os valores da população inicial, quando comparados com os valores dos tratamentos contendo solo + material vegetal, demonstram o efeito dos voláteis, das condições de anaerobiose e dos períodos de avaliação sobre a diminuição da viabilidade das estruturas dos fungos (Tabela 1).

Não foi constatada diferença entre os períodos para a população inicial (Tabela 1), isso explica o porquê do mesmo ter sido utilizado como referência para a transformação dos demais dados para base 100 na análise estatística.

Para nenhum tratamento e em nenhum dos períodos avaliados foi observada a erradicação das estruturas de resistência. Todavia, verificou-se uma tendência de diminuição do inóculo no decorrer do tempo para a maioria dos tratamentos contendo solo + material vegetal (Tabela 1). Embora Ambrósio et al. (1) tenham obtido 100\% de inibição das estruturas desses patógenos, esse fato não foi observado no presente trabalho. Esta observação procede, certamente, em virtude da diferença entre as metodologias aplicadas, onde as estruturas de resistência também sofreram a interferência dos microrganismos presentes no solo (1), indicando que houve influência de antagonistas (13), juntamente com a ação dos compostos voláteis e da condição de anaerobiose. Há relato de aumento da população de bactérias líticas em solo solarizado com a incorporação de resíduos de crucíferas no controle de $M$. phaseolina (18). No presente trabalho não houve a contribuição dos antagonistas, em função disto, houve apenas diminuição significativa da viabilidade das estruturas dos patógenos.

Para o brócolis foram identificados 26 compostos voláteis 
Tabela 1. Efeito de diferentes tratamentos submetidos a diferentes períodos sobre a sobrevivência de clamidósporos de Fusarium oxysporum f. sp. lycopersici raça 2, microescleródios de Macrophomina phaseolina e escleródios de Rhizoctonia solani AG-4 HGI e de Sclerotium rolfsii.

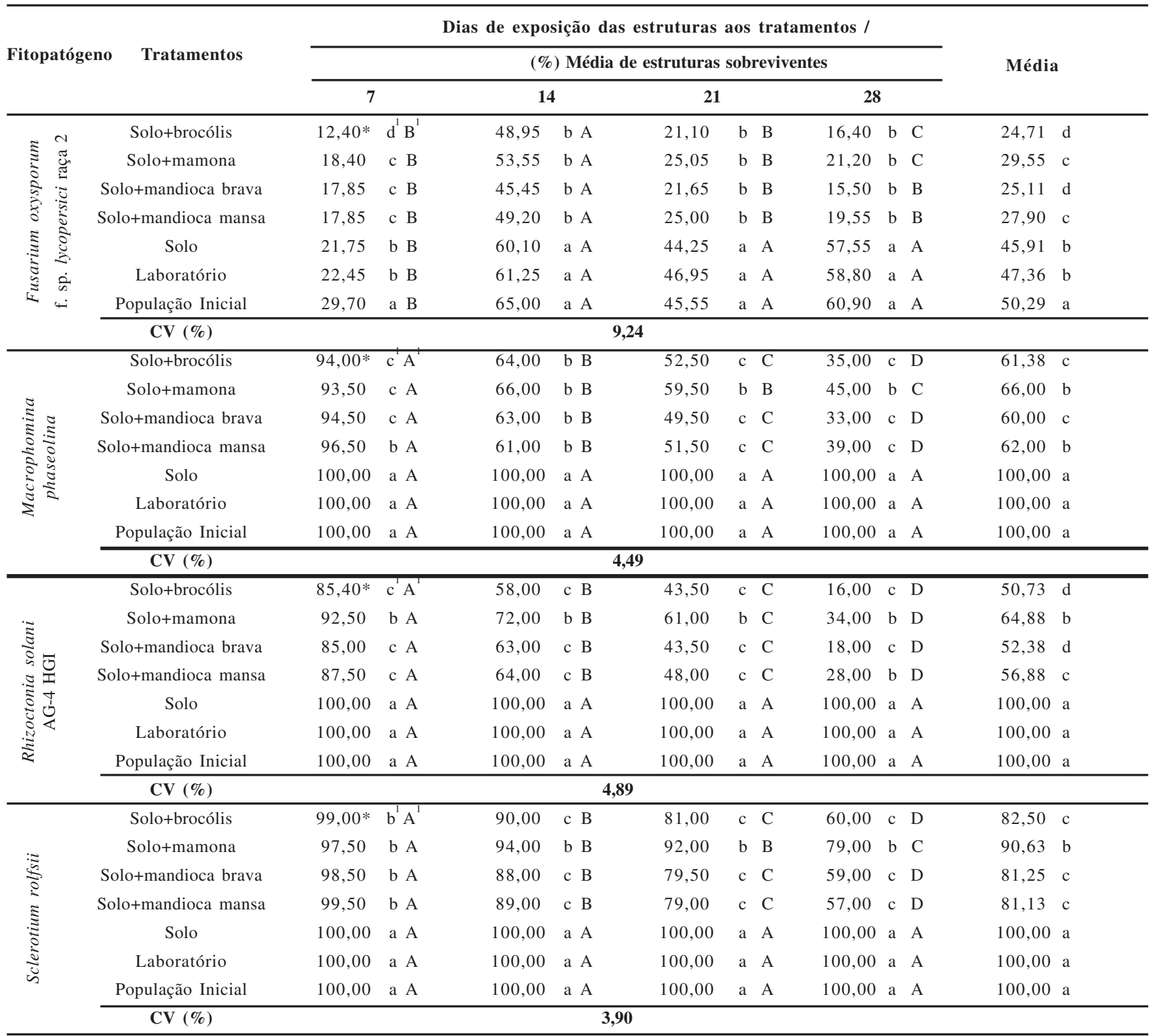

*Porcentagem referente à média de quatro repetições;

${ }^{1}$ Médias seguidas de mesma letra, minúscula na coluna e maiúscula na linha, não diferem entre si ao nível de 5\% de probabilidade, segundo o teste de Scott-Knott.

majoritários divididos em seis grupos de compostos: alcoóis (etanol, 1-propanol, 2-butanol, 2-metil-1 propanol, 1-butanol, 3-metil-1butanol, 2-metil-1-butanol, 1-hexanol e feniletilálcool), cetonas (acetona, 2-butanona, 2-pentanona e 3-octanona), ácidos (acético, butanóico e 2-metil-butanóico), ésteres (butanoato de metila, butanoato de butila, hexanoato de etila, 3-metil-butanoato de butila e 2-propenoato de 2-metilpentil), sulfurados (dimetilsulfeto, dimetildissulfeto, metilbenzilssulfeto e 5-metiltiopentanonitrila) e os chamados "outros" (2,5dimetilfurano) e não identificados (ni). Para a mamona detectaram-se 37 compostos voláteis divididos em cinco grupos, alcoóis (etanol, 1propanol, 2-butanol, 1-butanol, 3-metil-1-butanol, 2-metil-1-butanol, 3-hexen-1-ol e 1-hexanol), cetonas (acetona, 2-butanona, 3-pentanona e 2-heptanona), ácidos (acético, 2-metil-propanóico, butanóico, 3- metil-butanóico, 2-metil-butanóico e pentanóico, hexanóico), ésteres (butanoato de metila, acetato de 2-metil-propil, butanoato de etila, acetato de butila, 1-metil-butanoato de etila, butanoato de 2 metilpropil, 2metil-2-propenoato de propil, 2-butenoato de 1-metil-propil, butanoato de butila, 3-metil-butanoato de butila, 2 metil-2-propenoato de metilbutil, hexanoato de 2-metilpropil, butanoato de hexila, 3-metilbutanoato de hexila e hexanoato de 3-metil-butil) e "outros"( 2,5dimetilfurano, nonano e decano). Para mandioca mansa foram identificados 29 compostos voláteis e separados em cinco grupos, alcoóis (etanol, 2-butanol, 1-butanol, 2-pentanol, 3-metil-1-butanol, 3-hexen-1-ol e 1-hexanol), cetonas (acetona, 2-butanona, 2-pentanona, 3-pentanona e 3-octanona), ácidos (acético e butanóico), ésteres (butanoato de metila, acetato de 2-metil-propil, butanoato de etila, 3- 
Tabela 2. Análise de correlação de Pearson entre as áreas normalizadas dos compostos voláteis e do grupo de voláteis, oriundas da decomposição do brócolis, com os dados de sobrevivência de Fusarium oxysporum f. sp. lycopersici raça 2 (Fox), Macrophomina phaseolina (Macro), Rhizoctonia solani AG-4 HGI (Rhizo) e Sclerotium rolfsii (Scler) aos 7, 14, 21 e 28 dias.

\begin{tabular}{|c|c|c|c|c|c|c|c|c|c|}
\hline \multirow{2}{*}{$\begin{array}{l}\text { Grupo de } \\
\text { Volátil }\end{array}$} & \multirow{2}{*}{ Voláteis } & \multicolumn{2}{|c|}{ Fox } & \multicolumn{2}{|c|}{ Macro } & \multicolumn{2}{|c|}{ Rhizo } & \multicolumn{2}{|c|}{ Scler } \\
\hline & & "rr"1 & "p" & "r" & "p" & "r" & "p" & "r" & "p" \\
\hline \multirow[t]{3}{*}{ Álcoois } & 1-propanol & - & - & $0,96^{*}$ & $\mathrm{p}<0,05$ & - & - & - & - \\
\hline & 1-butanol & - & - & $0,96 *$ & $\mathrm{p}<0,05$ & - & - & - & - \\
\hline & Média $^{3}$ & - & - & $0,96^{*}$ & $\mathrm{p}<0,05$ & - & - & - & - \\
\hline \multirow{3}{*}{ Cetonas } & 2-butanona & - & - & $-0,97 *$ & $\mathrm{p}<0,05$ & $-0,98 *$ & $\mathrm{p}<0,05$ & $-0,97 *$ & $\mathrm{p}<0,05$ \\
\hline & 2-pentanona & - & - & - & - & - & - & $0,99 * *$ & $\mathrm{p}<0,01$ \\
\hline & Média ${ }^{4}$ & - & - & - & - & $-0,97 *$ & $\mathrm{p}<0,05$ & $-0,96 *$ & $\mathrm{p}<0,05$ \\
\hline \multirow[t]{2}{*}{ Ácidos } & ácido butanóico & - & - & $0,96 *$ & $\mathrm{p}<0,05$ & - & - & - & - \\
\hline & Média ${ }^{5}$ & $0,98 *$ & $\mathrm{p}<0,05$ & - & - & - & - & - & - \\
\hline Ésteres & butanoato de butila & - & - & $0,96^{*}$ & $\mathrm{p}<0,05$ & - & - & - & - \\
\hline Sulfurados & Média ${ }^{6}$ & - & - & $-0,99 * *$ & $\mathrm{p}<0,01$ & $-0,96 *$ & $\mathrm{p}<0,05$ & - & - \\
\hline "Outros" & - & - & - & - & - & - & - & - & - \\
\hline
\end{tabular}

metil-butanoato de etila, acetato de 3-metil-butil, butanoato de 2metilpropil, 2-metil-propanoato de butila, 2-metil-propanoato de 2metilpropil, 2-butenoato de 1-metil-propil, butanoato de butila, hexanoato de etila e 2-metil-propanoato de 3-metilbutil) e "outros" (2,5-dimetilfurano, isolimoneno e decano).

A particularidade da presença do grupo sulfurados no material de brócolis deve-se à alta quantidade do elemento enxofre em seus tecidos (81 $\mathrm{mg} \mathrm{x} \mathrm{dm}^{-3}$ ). Dentro dos sulfurados, vários compostos voláteis são apontados como responsáveis pela ação fungitóxica a fitopatógenos de solo $(8,10,12,14,18,24)$. Além do grupo dos sulfurados para o brócolis foram verificadas outras particularidades com relação aos compostos voláteis oriundos da decomposição da mamona e mandioca mansa. Isto evidência que existem diferenças qualitativas, tão ou mais importantes, dentro de cada grupo de voláteis observados no resultado das análises de cada material vegetal. Estas diferenças qualitativas explicam o efeito de cada um destes materiais vegetais com relação à redução da sobrevivência das estruturas de resistência dos fitopatógenos testados. Entretanto, é importante ressaltar que esta possível explicação, apesar de relevante, por si só não comprova o efeito diferencial destes compostos particulares de cada material sobre as estruturas dos fitopatógenos.

Nas Tabelas 2, 3 e 4 podem ser observados todos os voláteis oriundos da decomposição do brócolis, mamona e mandioca mansa, cujas áreas normalizadas ao longo dos períodos se correlacionaram de maneira significativa com a sobrevivência de cada fitopatógeno testado. A correlação pode ser positiva, indicando um comportamento diretamente proporcional entre as porcentagens dos voláteis e os dados de sobrevivência dos fungos, ou negativa, indicando um comportamento inversamente proporcional.

Para o brócolis, no grupo dos álcoois, verificou-se correlação positiva $(\mathrm{p}<0,05)$ para 1-propanol, 1-butanol e para a média do grupo apenas com relação a M. phaseolina (Tabela 2). No caso das cetonas, observou-se que 2-pentanona apresentou correlação positiva com a sobrevivência de $S$. rolfsii. Os 2-butanona e acetona apresentaram correlação negativa com a sobrevivência de M. phaseolina e $R$. solani AG-4 HGI e o 2-butanona correlação negativa com $S$. rolfsii e a média geral do grupo, também, correlacionou-se negativamente com $R$. solani e $S$. rolfsii. No grupo dos ácidos, o ácido butanóico e a média do grupo apresentaram correlação positiva com a sobrevivência de Macrophomina e Fusarium. Já no grupo dos ésteres, o butanoato de butila correlacionou-se positivamente com a sobrevivência de $M$. phaseolina. A média do grupo dos sulfurados, por sua vez, se correlacionou negativamente com Macrophomina e Rhizoctonia, enquanto que os chamados "outros" não se correlacionaram com a sobrevivência de nenhum dos fitopatógenos (Tabela 2).

Com relação aos voláteis oriundos da decomposição da mamona (Tabela 3), para o grupo dos alcoóis, assim como verificado para o brócolis, na sua maioria, se correlacionaram positivamente com a sobrevivência de M. phaseolina (etanol, 1-propanol e 3-hexen-1-ol e a média do grupo). O 3-hexen-1-ol correlacionou-se positivamente com Rhizoctonia. Os 2-butanol e 2-metil-1-butanol correlacionaram-se negativamente com a sobrevivência de M. phaseolina e Sclerotium, respectivamente. A média do grupo apresentou correlação negativa com $R$. solani. Para as cetonas, constatou-se correlação negativa para a 2-butanona com $R$. solani e positiva para o 2-heptanona com $M$. phaseolina. Já para os ácidos, todos os compostos apresentaram correlação negativa com a sobrevivência de $R$. solani. Já o ácido 3metil butanóico e a média do grupo correlacionaram-se negativamente com M. phaseolina e a média do grupo correlacionou-se positivamente com a sobrevivência de $R$. solani. Nos ésteres, ao contrário dos ácidos, constatou-se correlação positiva para a maioria dos compostos (butanoato de etila, 2-metil-2-propenoato de propil, 3-metil-butanoato de butila, 2 metil-2-propenoato de metilbutil, 3-metil-butanoato de hexila, hexanoato de 3-metil-butil e média geral do grupo) para $M$. 
Tabela 3. Análise de correlação de Pearson entre as áreas normalizadas dos compostos voláteis e do grupo de voláteis, oriundas da decomposição da mamona, com os dados de sobrevivência de Fusarium oxysporum f. sp. lycopersici raça 2 (Fox), Macrophomina phaseolina (Macro), Rhizoctonia solani AG-4 HGI (Rhizo) e Sclerotium rolfsii (Scler) aos 7, 14, 21 e 28 dias.

\begin{tabular}{|c|c|c|c|c|c|c|c|c|c|}
\hline \multirow{2}{*}{$\begin{array}{l}\text { Grupo de } \\
\text { Volátil }\end{array}$} & \multirow{2}{*}{ Voláteis } & \multicolumn{2}{|c|}{ Fox } & \multicolumn{2}{|c|}{ Macro } & \multicolumn{2}{|c|}{ Rhizo } & \multicolumn{2}{|c|}{ Scler } \\
\hline & & "r"' & "p" & "r" & "p" & "r" & "p" & "r" & "p" \\
\hline \multirow[t]{5}{*}{ Alcoóis } & etanol & - & - & $0,96^{*}$ & $\mathrm{p}<0,05$ & - & - & - & - \\
\hline & 1-propanol & - & - & $0,98 *$ & $\mathrm{p}<0,05$ & - & - & - & - \\
\hline & 2-butanol & - & - & $-0,99 * * *$ & $\mathrm{p}<0,001$ & - & - & - & - \\
\hline & 2-metil-1-butanol & - & - & - & - & - & - & $-0,99 * * *$ & $\mathrm{p}<0,001$ \\
\hline & Média ${ }^{3}$ & - & - & $0,96 *$ & $\mathrm{p}<0,05$ & $-0,99 * *$ & $\mathrm{p}<0,01$ & - & - \\
\hline \multirow[t]{2}{*}{$\overline{\text { Cetonas }}$} & 2-butanona & - & - & - & - & $-0,98^{*}$ & $\mathrm{p}<0,05$ & - & - \\
\hline & 2-heptanona & - & - & $0,97 *$ & , & - & - & - & - \\
\hline \multirow[t]{4}{*}{$\overline{\text { Ácidos }}$} & ácido 2-metil-propanóico & - & - & - & - & $-0,96^{*}$ & $\mathrm{p}<0,05$ & - & - \\
\hline & ácido 3-metil-butanóico & - & - & $-0,97 *$ & $\mathrm{p}<0,05$ & $-0,99 * *$ & $\mathrm{p}<0,01$ & - & - \\
\hline & ácido 2-metil-butanóico & - & - & - & - & $-0,96^{*}$ & $\mathrm{p}<0,05$ & - & - \\
\hline & Média $^{4}$ & - & - & $-0,96 *$ & $\mathrm{p}<0,05$ & $-0,96 *$ & $\mathrm{p}<0,05$ & - & - \\
\hline \multirow[t]{11}{*}{ Ésteres } & acetato de 2-metil-propil & - & - & - & - & $0,96^{*}$ & $\mathrm{p}<0,05$ & - & - \\
\hline & butanoato de etila & - & - & $0,97 *$ & $\mathrm{p}<0,05$ & - & - & - & - \\
\hline & 2metil-2-propenoato de propil & - & - & $0,97 *$ & $\mathrm{p}<0,05$ & - & - & - & - \\
\hline & 2-butenoato de 1-metil-propil & - & - & $0,96 *$ & $\mathrm{p}<0,05$ & $0,97 *$ & $\mathrm{p}<0,05$ & - & - \\
\hline & butanoato de butila & - & - & - & - & $0,96^{*}$ & $\mathrm{p}<0,05$ & - & - \\
\hline & 3-metil-butanoato de butila & - & - & $0,96 *$ & $\mathrm{p}<0,05$ & - & - & - & - \\
\hline & metil-2-propenoato de metilbutil & - & - & $0,98 *$ & $\mathrm{p}<0,05$ & - & - & - & - \\
\hline & hexanoato de 2-metilpropil & - & - & - & - & $-0,96 *$ & $\mathrm{p}<0,05$ & - & - \\
\hline & 3-metil-butanoato de hexila & - & - & $0,98 *$ & $\mathrm{p}<0,05$ & - & - & - & - \\
\hline & hexanoato de 3-metil-butil & - & - & $0,97 *$ & $\mathrm{p}<0,05$ & - & - & - & - \\
\hline & Média $^{5}$ & - & - & $0,97 *$ & $\mathrm{p}<0,05$ & - & - & - & - \\
\hline & decano & - & - & $0,99 * * *$ & $\mathrm{p}<0,001$ & - & - & - & - \\
\hline & Média ${ }^{6}$ & - & - & $0,96 *$ & $\mathrm{p}<0,05$ & $0,99 * * *$ & $\mathrm{p}<0,001$ & - & - \\
\hline
\end{tabular}

${ }^{1}$ "r" coeficiente de Pearson - pode variar de -1 a +1 , e quanto mais próximos desses valores, mais forte a associação das variáveis em exame. Quando zero, esse coeficiente indica ausência de correlação;

"2p" - probabilidade, referente ao nível de aceitação ou confiabilidade da correlação;

Médias respectivas dos grupos dos alcoóis, ácidos, esteres e "outros", oriundos da decomposição da mamona.

phaseolina, enquanto que o acetatato de 2-metil-propil e 2 butenoato de 1-metil-propil para $R$. solani e o hexanoato de 2-metilpropil negativamente com Rhizoctonia. Os nonano, decano e a média do grupo chamado de "outros" apresentaram correlação positiva com $M$. phaseolina, enquanto que somente o nonano e a média apresentaram correlação positiva para a sobrevivência de $R$. solani (Tabela 3).

Na mandioca mansa, um número menor de compostos apresentou correlação, seja ela negativa ou positiva para com a sobrevivência dos fitopatógenos (Tabela 4). No grupo dos álcoois, apenas o 3-hexen-1ol correlacionou-se positivamente com a sobrevivência de $M$. phaseolina, $R$. solani e $S$. rolfsii, sendo que a média do grupo, também, correlacionou-se positivamente com a sobrevivência de Fusarium. Nas cetonas, a 3-pentanona apresentou comportamento proporcional a sobrevivência de $M$. phaseolina e $R$. solani, enquanto que para o grupo dos ácidos não foi verificada qualquer correlação significativa com relação aos fungos. Nos ésteres oriundos da decomposição da mandioca mansa, observou-se um comportamento variável à correlação com a sobrevivência dos fungos testados. Foi constatada correlação positiva entre a porcentagem de butanoato de metila e 3-metil butanoato de etila para com Fusarium e butanoato de etila para $R$. solani. Correlação negativa foi observada para 2-metil-propanoato de butila e 2-metil-propanoato de 2-metilpropil para M. phaseolina e 2-metilpropanoato de 3-metilbutil para $R$. solani. A média do grupo dos "outros", por sua vez, apresentou correlação positiva para com a sobrevivência de $R$. solani e $S$. rolfsii, sendo o 2,5-dimetilfurano, em específico, com Fusarium (Tabela 4).

Os grupos de voláteis ou voláteis que apresentaram correlação negativa com a sobrevivência dos fitopatógenos podem ser apontados como os mais promissores no que diz respeito ao controle das estruturas de resistência dos fungos estudos, uma vez que sua concentração aumenta com o tempo ao ponto que a sobrevivência diminui. Há relato de gases de isotiocianatos emanados principalmente a partir de plantas de Brássicas no controle de $F$. oxysporum var. radicis (24) e de outros fitopatógenos (14). Há poucos estudos que apontam gases potenciais fungitóxicos oriundos de outras plantas que possam estar correlacionados no 
Tabela 4. Análise de correlação de Pearson entre as áreas normalizadas dos compostos voláteis e do grupo de voláteis, oriundas da decomposição da mandioca, com os dados de sobrevivência de Fusarium oxysporum f. sp. lycopersici raça 2 (Fox), Macrophomina phaseolina (Macro), Rhizoctonia solani AG-4 HGI (Rhizo) e Sclerotium rolfsii (Scler) aos 7, 14, 21 e 28 dias.

\begin{tabular}{|c|c|c|c|c|c|c|c|c|c|}
\hline \multirow{2}{*}{$\begin{array}{l}\text { Grupo de } \\
\text { Volátil }\end{array}$} & \multirow{2}{*}{ Voláteis } & \multicolumn{2}{|c|}{ Fox } & \multicolumn{2}{|c|}{ Macro } & \multicolumn{2}{|c|}{ Rhizo } & \multicolumn{2}{|c|}{ Scler } \\
\hline & & "r"r" & "p" & "r" & "p" & "r" & "p" & "r" & "p" \\
\hline \multirow[t]{2}{*}{ Álcoois } & 3-hexen-1-ol & - & - & $0,96^{*}$ & $\mathrm{p}<0,05$ & $0,99 * *$ & $\mathrm{p}<0,01$ & $0,97 *$ & $\mathrm{p}<0,05$ \\
\hline & Média $^{3}$ & $0,96 *$ & $\mathrm{p}<0,05$ & - & - & - & - & - & - \\
\hline Cetonas & 3-pentanona & - & - & $0,99 * * *$ & $\mathrm{p}<0,001$ & $0,98 *$ & $\mathrm{p}<0,05$ & - & - \\
\hline Ácidos & - & - & - & - & - & - & - & - & - \\
\hline \multirow[t]{6}{*}{ Ésteres } & butanoato de metila & $0,97 *$ & $\mathrm{p}<0,05$ & - & - & - & - & - & - \\
\hline & butanoato de etila & - & - & - & - & $0,96 *$ & $\mathrm{p}<0,05$ & - & - \\
\hline & 3-metil-butanoato de etila & $0,98 *$ & $\mathrm{p}<0,05$ & - & - & - & - & - & - \\
\hline & 2-metil-propanoato de butila & - & - & $-0,96 *$ & $\mathrm{p}<0,05$ & - & - & - & - \\
\hline & 2-metil-propanoato de 2-metilpropil & - & - & $-0,99 * *$ & $\mathrm{p}<0,01$ & - & - & - & - \\
\hline & 2-metil-propanoato de 3-metilbutil & - & - & - & - & $-0,96 *$ & $\mathrm{p}<0,05$ & - & - \\
\hline \multirow[t]{2}{*}{ "Outros" } & 2,5-dimetilfurano & $0,99 * *$ & $\mathrm{p}<0,01$ & - & - & - & - & - & - \\
\hline & Média $^{4}$ & - & - & - & - & $0,96 *$ & $\mathrm{p}<0,05$ & $0,99 * *$ & $\mathrm{p}<0,01$ \\
\hline
\end{tabular}

"r" coeficiente de Pearson - pode variar de $-1 \mathrm{a}+1$, e quanto mais próximos desses valores, mais forte a associação das variáveis em exame. Quando zero, esse coeficiente indica ausência de correlação;

2"p" - probabilidade, referente ao nível de aceitação ou confiabilidade da correlação;

Médias respectivas dos grupos dos alcoóis e "outros", oriundos da decomposição da mandioca mansa.

controle de fitopatógenos, fato este assinalado pelo presente trabalho.

A purificação de um gás especificamente ou de vários e até a sua sintetização e o contato deste ou destes gases frente ao patógeno com o intuito de comprovar a sua eficácia no controle, é pouco estudada. Além disto, o conhecimento adquirido no presente trabalho a respeito da correlação positiva ou negativa e a média do grupo versus a sobrevivência das estruturas dos fungos testados irá auxiliar na elaboração de metodologias para futuros testes com compostos voláteis, isoladamente ou em associação, quanto à sobrevivência das estruturas dos fitopatógenos. Assim, identificar-se-á, conclusivamente, o (s) composto (s) volátil (eis) responsável (eis) pela inibição das estruturas dos fungos.

\section{AGRADECIMENTOS}

Agradecemos a Fundação de Amparo à Pesquisa do Estado de São Paulo pela concessão do Auxílio à Pesquisa (FAPESP: 07/50895-3) e a Coordenação de Aperfeiçoamento de Pessoal de Nível Superior (CAPES) pela bolsa de estudos outorgada ao primeiro autor do presente trabalho.

\section{REFERENCIAS BIBLIOGRÁFICAS}

1. Ambrósio, M. M. Q.; Bueno, C. J.; Padovani, C. R.; Souza, N. L. Controle de fitopatógenos do solo com materiais vegetais associados à solarização. Summa Phytopathologica, Botucatu, v. 34, n. 3, p. 354-358, 2008.

2. Arthur, C. L.; Pawliszyn, J. SPME with thermal desorption using fused silica optical fibers. Analytical Chemistry, Washington, v. 62, p. 2145-2148, 1990.

3. Blok, W. J.; Lamers, J. G.; Termorshuizen, A. J.; Bollen, G. J. Control of soilborne plant pathogens by incorporating fresh organic amendments followed by tarping. Phytopathology, St. Paul, v. 90, n. 3, p. 253-259, 2000.

4. Bueno, C. J.; Ambrósio, M. M. Q.; Souza, N. L. Produção e avaliação da sobrevivência de estruturas de resistência de fungos fi- topatogênicos habitantes do solo. Summa Phytopathologica, Botucatu, v. 33, n. 1, p. 47-55, 2007.

5. Cloud, G. L. Comparison of three media for enumeration of sclerotia of Macrophomina phaseolina. Plant Disease, St. Paul, v. 75, n. 8, p. 771-772, 1991.

6. Cruz, J. C. S.; Rocha, M. M.; Souza, N. L.; Padovani, C. R.; Minhoni, M. T. A. Aspectos microbiológicos do solo e a técnica de solarização. Summa Phytopathológica, Botucatu, v. 31, n. 1, p. 72-81, 2005.

7. DeNobilli, M.; Contin, M.; Mondini, C.; Brookes, P. C. Soil microbial biomass in triggered into actvity by trace amounts of substrate. Soil Biology and Biochemistry, Oxford, v.3 3, n. 9, p. 1161-1170, 2001.

8. Duncan, A. Glucasinolates. In: D' Mello, J. P.; Duffus, C. M.; Duffus, J. H. (Eds.). Toxic substances in crop plants. Cambridge: Royal Society of Chemistry, 2001. p. 127-147.

9. Embrapa. Centro Nacional de Pesquisa de Solos. Sistema brasileiro de classificação de solos. Rio de Janeiro, 1999. 412 p.

10. Freire, M. F. I.; Morra, M. J.; Knudsen, G. R. Atividade antifúngica de substâncias voláteis presentes em Brassicas napus sobre o crescimento micelial de Fusarium oxysporum. Revista Brasileira de Farmácia, Rio de Janeiro, v. 85, n. 3, p. 73-75, 2004.

11. Gamliel, A.; Stapleton, J. J. Characterization of antifungal volatile compounds envolved from solarizes soil amended with cabbage residues. Phytopathology, St. Paul, v. 83, p. 899-905, 1993 (a).

12. Gamliel, A.; Stapleton, J. J. Effect of soil amendment with chicken compost or ammonium phosphate and solarization on pathogen control, rhizosphere microorganisms and lettuce growth. Plant Disease, St. Paul, v. 77, p. 886-891, 1993 (b).

13. Ghorbani, R.; Wilcockson, S.; Koocheki, A.; Leifert, C. Soil management for sustainable crop disease control: a review. Environmental Chemistry Letters, Berlin, v. 6, p. 149-162, 2008.

14. Kirkegarrd, J. A.; Sawar, M. Glucosinolates profalis of Australian canola (Brassica napus annua L.) and Indian mustard (Brassica juncea L.) cultivars: implications for biofumigation. Australian Journal of Agricultural Researh, Collingwood, v. 50, p. 315324, 1999.

15. Ko, W.; Hora, F. K. A selective medium for Rhizoctonia solani in soil. Phytopathology, St. Paul, v. 61, n. 6, p. 707-710, 1971.

16. Komada, H. Development of a selective medium for quantitative 
isolation of Fusarium oxysporum from natural soil. Review of Plant Protection Research, Tokyo, v. 8, p. 114-124, 1975.

17. Lefèvre, A. F.; Souza, N. L. Determinação da temperatura letal para Rhizoctonia solani e Sclerotium rolfsii e efeito da solarização sobre a temperatura do solo. Summa Phytopathologica, Jaguariúna, v. 19, n. 2, p. 107-112, 1993.

18. Lodha, S.; Sharma, S. K.; Aggarwal, R. K. Solarization and natural heating of irrigated soil amended with cruciferous residues for improved control of Macrophomina phaseolina. Plant Pathology, London, v. 46, p. 186-190, 1997.

19. Matthiessen, J. N.; Shackleton, M. Biofumigation: environmental impacts on the biological activity of diverse pure and plantderived isothiocyanates. Pest Manage Science, Wembley, v. 61, p. 1043-1051, 2005.

20. Rosa, E. A. S.; Heaney, R. K.; Fenwick, G. R. Glucosinolates in crop plants. Horticultural Reviews, New York, v. 19, p. 99215, 1997

21. Ramirez-Villapudua, J.; Munnecke, D. E. Control of cabbage yellows (Fusarium oxysporum f. sp. couglutinans) by solar heating of field soil amended with dry cabbage residues. Plant Disease, St. Paul, v. 78, p. 289-295, 1988.

22. Souza, N. L. Interação entre solarização e incorporação prévia de matéria orgânica no solo. Summa Phytopathologica, Botucatu, v. 30, n. 1, p. 142-145, 2004.

23. Souza, N. L.; Bueno, C. J. Sobrevivência de clamidósporos de Fusarium oxysporum f. sp. lycopersici Raça 2 e Sclerotium rolfsii em solo solarizado incorporado com matéria orgânica. Summa Phytopathologica, Botucatu, v. 29, n. 2, p. 153-160, 2003.

24. Smolinska, U.; Horbowick, M. Fungicidal activity of volaties from selected cruciferous plants against resting propagules of soil-borne fungal pathogens. Journal of Phytopathology, Berlin, v. 147, p. 119-124, 1999.

25. Valente, A. L. P.; Augusto, F. Microextração em fase sólida. Química Nova, São Paulo, v. 23, n. 4, p. 523-530, 2000.

26. Wyllie, T. D.; Gangopadhyay, S.; Teague, W. R.; Blanchar, R. W. Germination and production of Macrophomina phaseolina microsclerotia as affected by oxygen and carbon dioxide concentration. Plant and Soil, Dordrecht, v. 81, p. 195-201, 1984. 